Revista Digital Universitaria

Vol. 22, Núm. 6, noviembre-diciembre 2021

\title{
Nuevas formas de enfrentar la realidad
}

\author{
Rosa María del Ángel y Morgana Carranco
}

E s indudable que los y las docentes buscan constantemente formas más efectivas e innovadoras de enseñar. En los últimos 18 meses, esta búsqueda se ha vuelto aún más acentuada, ya que la covid-19 sacudió el panorama universitario y escolar, así como el mundo académico, lo que empujó a los docentes a experimentar con nuevas estrategias para incentivar a sus estudiantes. Actualmente, si hacemos una breve búsqueda en internet, podemos encontrar varios métodos de enseñanza innovadores, desde el aula invertida, conferencias digitalizadas o en línea — como tareas previas a la clase-, comunidades de práctica e investigación, hasta dictar la sesión en un canal de YouTube o un podcast.

Además, los y las estudiantes lograron nuevas habilidades con la educación remota y a distancia; por ejemplo, participar en experiencias de aprendizaje activas como discusiones, enseñanza entre pares, presentaciones, proyectos, resolución de problemas, cálculos y actividades grupales. En otras palabras, consideramos que es importante destacar las estrategias emergentes, innovadoras, creativas o alternativas que son más efectivas para garantizar una educación de calidad para todos, incluso en medio de una crisis de salud. Y, sobre todo, queremos recalcar el valor de no dejar de lado las disparidades digitales y buscar propuestas que sirvan para aliviar algunas de las cargas de los estudiantes, maestros y centros escolares.

En este sentido, y debido a que la unam y las instituciones educativas de nuestro país no se detienen, los autores y autoras del último número del año de la Revista Digital Universitaria nos comparten algunas herramientas, estrategias, experiencias, testimonios y resultados de investigaciones, que se lograron en este segundo año de pandemia.

Como es costumbre, abrimos con los artículos de divulgación de la sección Varietas. Aquí destacan la diversidad natural, a distintos niveles, por ejemplo, la que hay en los "Micromundos biominerales en las algas rojas" y la de las diferencias de "La pigmentación en la piel humana como adaptación al ambiente". En este último texto, además, los autores resaltan la importancia de la ciencia, la cual en ciertas ocasiones es utilizada como instrumento de marginación y discriminación. 
"Nuevas formas de enfrentar la realidad" Rosa María del Ángel y Morgana Carranco Vol. 22, Núm. 6, noviembre-diciembre 2021

Revista Digital Universitaria

Otro asunto está ubicado precisamente, en el ámbito de la marginación social. En "La importancia de la inteligencia emocional en la población masculina", la autora aborda el tema de la inteligencia emocional enfocada en los hombres, como pieza clave contra la violencia de género y el sistema patriarcal, así como la relevancia de perseguir nuevas áreas de investigación sobre el tema.

Y por último, sobresale la importancia del análisis de datos y sus aplicaciones, que pueden proporcionar grandes beneficios, desde "Una red neuronal para la detección de somnolencia en conductores", pasando por el "Desarrollo de nuevos fármacos por computadora", hasta la reflexión de si la evolución del "Sistema de archivos, gestores de base de datos y Hadoop en los negocios se puede considerar realmente una evolución o un retroceso.

En cuanto a la importancia de apoyar las estrategias emergentes para garantizar una educación de calidad, varias escuelas alentaron a los y las docentes a encontrar nuevas formas de enseñanza, lo que les llevó a grabar sus clases o a crear recursos digitales complementarios, mediante podcasts, cápsulas informativas, blogs, memes e infografías. Es por ello que en Caleidoscopio se habla de la "Infografía, la mirada creativa de la información", como una herramienta útil y necesaria para compartir el conocimiento.

Sin embargo, a veces, adoptar nuevas formas de enseñanza puede ser desalentador, y resultar en una barrera significativa para pasar al formato digital o para encontrar las didácticas más adecuadas para la educación a distancia y en línea, pero, en el contexto actual, es un compromiso que tanto docentes como estudiantes debemos adquirir para sacar adelante de la mejor forma la continuidad educativa. En nuestra sección Continuum educativo, compartimos las experiencias de "Lo que aprendimos a un año de haber comenzado la pandemia"y de cómo nuestros profesores no se rinden al "Buscar el mejoramiento docente en la educación a distancia".

Sin duda, el cambio hacia el aprendizaje en línea ha planteado muchos desafíos para los maestros, los centros escolares y las familias, en particular aquellos situados en comunidades rurales, de bajos ingresos y sin acceso a internet de alta velocidad. Actualmente, algunos estudiantes están haciendo todo lo posible para acceder a una conexión Wi-Fi, incluso sentados en las banquetas o en las escaleras de escuelas y bibliotecas cerradas. En la sección Universidades, encontrarás lo que se está haciendo para enfrentar las dificultades que trajo el coronavirus SARS-CoV-2. En cuanto a diferentes instituciones, en "De la política internacional al Programa Emergente de Educación Remota de la Universidad Autónoma Metropolitana", su autor nos platica lo que se ha hecho en esta institución mexicana de educación superior . Con respecto a otros lugares, el texto "Afrontamiento durante la pandemia: experiencias psicosociales de los amuzgos de Xochistlahuaca" cuenta las dificultades que esta comunidad rural de Guerrero tuvo que enfrentar durante la pandemia, y no sólo en el contexto educativo sino en su forma de vida.

La pandemia aún no termina, queda un largo trecho por recorrer, pero creemos que este podría ser un buen momento para experimentar, mirar más allá de las soluciones a corto plazo y desplegar recursos para catalizar la transformación de 
"Nuevas formas de enfrentar la realidad" Rosa María del Ángel y Morgana Carranco Vol. 22, Núm. 6, noviembre-diciembre 2021

Revista Digital Universitaria

este y los siguientes años. Adoptemos las bondades del aprendizaje virtual como una nueva manera que va más lejos de la idea de que una misma forma de educar o un sólo modelo pedagógico sirve para todos los estudiantes, que nuestro tiempo como maestros y/o estudiantes durante la educación remota nos haga creer en nuestra capacidad y habilidades, ya demostradas en la mayoría de los casos, para asumir desafíos académicos, que nos inspiren a construir una base de confianza a la que recurramos a lo largo de nuestras vidas. Así como un entendimiento y diálogo académicos más profundos y relevantes a los tiempos venideros en las instituciones de educación superior. Sigamos buscando el conocimiento y compartiéndolo con nuevas y alternativas estrategias y métodos, diseñando formas innovadoras y más creativas de enseñar y aprender. La educación en línea y a distancia no es la panacea educativa, pero sí ha constituido la alternativa en una crisis de salud y educativa sin precedente en el último siglo en el mundo. Es impostergable innovar en educación ante crisis similares por consecuencias del cambio climático o eventos de desastre natural, se requiere que pensemos en la profesionalización docente y en las nuevas formas de educarnos en situaciones de huracanes, temblores o terremotos, incendios, inundaciones u otras circunstancias que obliguen a la educación a continuar. Y recuerda que la Revista Digital Universitaria está aquí para contribuir con esta misión.

\section{Cómo CITAR ESTE ARTículo}

* del Ángel Martínez, Rosa María y Carranco, Morgana. (2021, noviembre-diciembre). Nuevas formas de enfrentar la realidad. Revista Digital Universitaria (RDU), 22(6). http://doi. org/10.22201/cuaieed.16076079e.2021.22.6.0 
"Nuevas formas de enfrentar la realidad" Rosa María del Ángel y Morgana Carranco Vol. 22, Núm. 6, noviembre-diciembre 2021

Revista Digital Universitaria

Rosa María del Ángel Martínez

rosa_martinez@cuaieed.unam.mx orcid.org/0000-0001-7655-0314

Estudió la licenciatura en Creación literaria y se ha especializado en la edición de revistas y libros electrónicos. Inició su formación profesional como becaria de la Revista Digital Universitaria (RDU), donde hizo la labor de corrección de estilo y maquetación de pdfs. Posteriormente, colaboró en el Proyecto de Digitalización del Acervo Historia de la Revista de la Universidad de México y en el Proyecto de digitalización del Acervo Histórico de la Gaceta UnAm, que corrieron a cargo del área de Acervos Digitales de la Dirección General de Tecnologías de la Información y Comunicaciones (DGTIC). Al mismo tiempo, colaboró en el Proyecto Universitario del Libro Electrónico para la Dirección General de Publicaciones y Fomento Editorial (DGPyFE), en el cual produjo y editó libros y tesis en formato ePub 2 y 3. Además, formó parte del equipo a cargo del proyecto Digitalización de las Obras Completas de Francisco Hernández. También, perteneció al equipo de Revistas unam en donde desempeñó actividades como: configuración de la plataforma ojs 2 y 3, asesorías a editores, autores y equipos editoriales para la gestión de la plataforma y seguimiento del proceso editorial de una revista electrónica. Asimismo, ha impartido talleres de producción y edición de eBook básico y avanzado como parte del Programa de Apoyo a la Profesionalización de la Actividad Editorial organizado por la DGPYFE. Actualmente funge como editora asociada de la Revista Digital Universitaria.

\section{Morgana Carranco}

morgana.carranco@gmail.com orcid.org/0000-0002-2520-2560

Estudió la Licenciatura en Ciencias Genómicas, la Licenciatura en Lengua y Literaturas Hispánicas y la Maestría en Letras (Letras Mexicanas) en la Universidad Nacional Autónoma de México (UNAM). En 2017 fue seleccionada para participar en la Beca Juan Grijalbo, Seminario de Introducción al Mundo del Libro y la Revista, organizada por la CANIEM. Actualmente es editora técnica y correctora de estilo en la Revista Digital Universitaria, publicación de la unAm para la comunicación social de las ciencias, las humanidades y las artes. Sus líneas de investigación son la figura de la bruja, la literatura fantástica y la comunicación social del conocimiento. Forma parte del Seminario de Literatura Fantástica Hispanoamericana de la unam. 